\title{
DE LA LINGÜÍSTICA A LA EDUCACIÓN: IDEARIO EDUCATIVO DEL DR. VÍCTOR ML. SÁNCHEZ CORRALES
}

\author{
Marielos Murillo Rojas
}

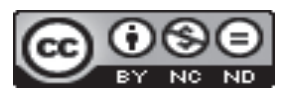

Esta obra está bajo una licencia Creative Commons

Reconocimiento-No Comercial-Sin Obra Derivada 



\title{
DE LA LINGÜÍSTICA A LA EDUCACIÓN: IDEARIO EDUCATIVO DEL DR. VÍCTOR ML. SÁNCHEZ CORRALES
}

\author{
FROM LINGUISTICS TO EDUCATION: EDUCATIONAL IDEOLOGY OF \\ DR. VÍCTOR ML.SÁNCHEZ CORRALES
}

Marielos Murillo Rojas

\begin{abstract}
RESUMEN
En este artículo se presentan las ideas y propuestas teórico-metodológicas del Dr. Víctor M1. Sánchez Corrales sobre la enseñanza de la lengua española en el sistema educativo costarricense: sustitución del modelo de lengua como arte y del correspondiente método gramatical en su didáctica por el concepto diasistémico de la lengua y el enfoque comunicativo como la mediación pedagógica con más pertinencia.

Palabras clave: planificación lingüística, lingüística educativa, lengua española, enfoque comunicativo, Sánchez Corrales-Víctor.
\end{abstract}

\section{ABSTRACT}

This article is about Dr. Víctor Ml. Sánchez Corrales's ideas and theoretical-methodolgical proposals regarding teaching the Spanish language in the Costa Rican educational system: a substitution of the model of language as an art and the corresponding grammatical approach in teaching it for the diasystematic concept of language and the communicative approach as the most pedagogically pertinent method.

Key words: Linguistic planning, educational linguistics, Spanish language, Communicative approach, Sánchez Corrales-Víctor.

El vocablo maestro puede asociarse con conceptos como: enseñanza, aprendizaje, estudio, orientación, guía, generosidad, ejemplo, dedicación, compromiso, amor, responsabilidad social, promoción humana, etc. y con personas destacadas que han dedicado su vida a esculpir ideas, sembrar semillas, cuidar cultivos y obsequiar frutos. El maestro proyecta una claridad comparable con la requerida por la planta al realizar el proceso de fotosíntesis. Maestro, por tanto, no es solo quien enseña sino aquel que vive la vida como vocación de servicio. El Dr. Víctor Ml.

Dra. Marielos Murillo Rojas. Universidad de Costa Rica. Profesora en Escuela de Formación Docente. Costa Rica.

Correo electrónico: marielosmuro@gmail.com

Recepción: 17- 02- 2014

Aceptación: 18- 03- 2014 
Sánchez Corrales, lingüista y profesor de enseñanza media y universitaria, es el maestro que, gracias a la generosidad del Dr. Carlos Sánchez Avendaño, presento en el marco de la II Semana de Diversidad Lingüística, realizada en noviembre de 2013 en la Universidad de Costa Rica.

Don Víctor, como le llamamos sus alumnos, estudió las carreras de profesorado en Filosofía y en Enseñanza del Castellano y Literatura, a mediados de la década del 60 del siglo XX; momento en que se encuentra con las teorías de la educación, se acerca al contexto educativo nacional, adquiere conocimientos de su disciplina y empieza a profesar una ética profesional y una filosofía de vida, en la que se encarna su vocación de maestro.

Posteriormente, don Víctor complementa su formación académica, estudia lingüística y se especializa en romanística, sustento teórico-académico que motiva su principal preocupación desde el ámbito de la educación:

¿Cómo puede contribuir la lingüística al mejoramiento de la enseñanzaaprendizaje de la lengua española en la educación costarricense?

La respuesta a ese cuestionamiento se plasma inicialmente en los artículos "Análisis del concepto de lengua española en la educación costarricense" (1989) y "La enseñanza del español en la educación preescolar costarricense" (1993), documentos que develan el concepto de lengua y su enseñanza, el cual, en palabras del autor, es básicamente un modelo de corrección idiomática sustentado en el uso culto del texto escrito de autores clásicos, "de escritos serios: declaraciones de hombres de Estado, edictos, enseñanza de cátedra, discursos judiciales, etc." y en el uso de la lengua en situaciones formales:

Durante la Colonia, las sociedades americanas más jerarquizadas -México y Perú- tenían una relación estrecha e institucionalizada con España, por medio de la Corona y de la Iglesia. Como consecuencia lingüística de este hecho, en la enseñanza de la lengua española se tomó como variante de prestigio y modelo de corrección idiomática el uso culto del español peninsular, toledano primero y madrileño después. Tal situación valorativa del período colonial, perdura hasta nuevos días, cuya preceptiva depende del grado de identidad cultural de las naciones hispanoamericanas. (Sánchez-Corrales, 1993, p. 109)

Así las cosas la enseñanza de la lengua española en Costa Rica, llamada antes lengua materna, se ha fundamentado en la doctrina gramatical de la academia y, en menor grado, a partir de 1941, en las aportaciones teóricas de don Andrés Bello. En ambos casos la gramática es arte: es necesario aprender ciertos principios idiomáticos, que se abstraen del uso culto y, en particular, del discurso literario, para hablar bien. (Sánchez-Corrales, 1989, p. 156)

Ambos artículos demuestran acuciosamente que la norma académica es el modelo que impera en la educación preescolar, primaria, secundaria y universitaria costarricenses, paradigma que excluye la discusión y estudio de las variaciones de la lengua desde una perspectiva diasistémica.

Ante esta situación, don Víctor, presenta una propuesta titulada 'Redefinición del concepto de lengua española en la educación costarricense', en la cual aboga por un cambio de paradigma, pasar de un modelo a otro: del académico al sociolingüístico, esto es, diasistémico en el que se valore la diversidad de usos, variedades y estilos y, reemplazar la noción de corrección idiomática por el concepto de adecuación comunicativa.

Enseñar lengua española en Costa Rica quiere decir, según nuestro criterio, enseñar el español de Costa Rica como un haz de variedades lingüísticas cuyos elementos tienen "similar distribución social" [...], una de las cuales, por razones socioculturales y de planificación lingüística, se ha de erigir como código en situaciones de comunicación sobre temas formales, con participantes formales y canales de comunicación formales. [...] Enseñar español en la educación costarricense ha de ser enseñar las distintas variedades del español de Costa Rica, de modo que el educando pueda desenvolverse adecuadamente, según la situación comunicativa. (Sánchez, 1989, p. 158) 
En este mismo artículo, el autor esboza el camino por seguir, otorgando a la investigación sociolingüística y lingüístico-educativa un espacio vital en la descripción de los usos lingüísticos de los educandos, del discurso pedagógico, en diferentes niveles y el estudio la norma culta costarricense y su proyección al sistema educativo nacional. De esta forma inician los estudios sobre el capital lingüístico de los educandos en los niveles: léxico, morfosintáctico, discursivo y fonológico.

Las ideas esculpidas por nuestro maestro, muchas desarrolladas por él mismo mediante la investigación y otras puestas en manos de sus alumnos, se cristalizan en las siguientes líneas de estudio:

a. Análisis del concepto de lengua española en la educación costarricense.

b. Descripción de los modelos de enseñanza de la lengua española en Costa Rica en diferentes niveles del sistema educativo.

c. Evidencia la necesidad de la planificación lingüístico-curricular y del trabajo conjunto entre pedagogos y lingüistas.

d. La investigación como piedra angular para la planificación lingüística.

e. Estudios sobre la competencia lingüístico-comunicativa de los educandos y el uso lingüístico culto costarricense en su condición de variedad meta del proceso de enseñanza aprendizaje.

f. La elaboración de diccionarios didácticos.

g. La didáctica del vocabulario, componente de la lengua estudiado más ampliamente.

Adicionalmente, don Víctor ha mostrado una gran preocupación por la formación inicial del maestro y del profesor, por la necesidad de un cambio y enriquecimiento de los conocimientos sobre la lengua y su correspondiente actuación pedagógica, tanto en primaria como en secundaria. Muestra de ese compromiso son las diez tesis de grado y posgrado que dirigió sobre temas de lingüística educativa, en las áreas de: adquisición y aprendizaje de vocabulario, madurez sintáctica en diferentes niveles educativos, planificación lingüísticoeducativa, vocabularios básicos y disponibles en preescolar, primaria y secundaria, problemas en la adquisición de la fonética y la fonología, por citar algunos temas bajo su dirección.

Respecto de las prácticas pedagógicas, es destacable el recorrido que hizo don Víctor por todo el territorio nacional, no solo recogiendo información para sus corpus lingüísticos, sus estudios dialectológicos e inventarios léxicos, sino brindando acompañamiento y asesoramiento a profesores de español de secundaria, en coordinación con las asesorías regionales del Ministerio de Educación; espacios en los que promovió el cambio de paradigma en la enseñanza de la lengua, del modelo de corrección idiomática al de adecuación comunicativa, a partir de los siguientes postulados:

a. Pasar del metalenguaje a la producción y comprensión textuales.

b. Priorizar el desarrollo de las competencias respecto de la enseñanza-aprendizaje de contenidos.

c. Reemplazar al alumno receptor pasivo por el alumno constructor de conocimientos.

d. Sustituir al magister ex cátedra por un guía en el proceso de construcción de conocimientos. 
e. Presentar materiales didácticos enfocados hacia la producción y construcción de conocimientos, en correspondencia con las competencias cultivadas en los estudiantes.

f. Desplazar los criterios de evaluación tradicionales por otros que respondan al desarrollo de las competencias comunicativas de los escolares, según su nivel evolutivo $\mathrm{y}$ en correspondencia con un tratamiento integrado y secuencial de las competencias específicas por desarrollar.

El enfoque comunicativo, tal como lo presenta el autor, es en esencia una propuesta eminentemente didáctica que pone énfasis en los distintos usos de la lengua y en la necesidad de propiciar en los estudiantes la competencia comunicativa, entendida como aquel conjunto de conocimientos lingüísticos y habilidades comunicativas que se van adquiriendo a lo largo del procesos de socialización de las personas.

Por otra parte, la faceta de lexicógrafo, según mi opinión, la más robusta en la vida académica de don Víctor, lo motiva a no solo hacer diccionarios, estudiar el léxico del español de Costa Rica, formar un equipo de investigación y un programa de lexicografía, sino también a ocuparse de la enseñanza del vocabulario, componente de la lengua, en que su aporte es destacable.

Es de autoría de nuestro autor el concepto de léxico meta y léxico objeto, tal como hoy se entiende en las políticas educativas nacionales:

a. El léxico objeto corresponde al inventario de vocablos obtenido a partir de la competencia comunicativa de los educandos; conocimiento fundamental para planificar la enseñanza del vocabulario.

b. El léxico meta comprende el vocabulario técnico de las diferentes asignaturas (Matemáticas, Estudios Sociales, Ciencias y Español) y el de mediación pedagógica.

Ambos conceptos están incorporados en los programas de estudio de Español, I y II ciclo de la Educación General Básica; a partir de ahora el docente debe identificar el vocabulario técnico de las asignaturas o temáticas curriculares y estudiarlo previamente para favorecer los procesos de comprensión y el enriquecimiento del vocabulario del educando; con esta medida se logra concretizar el cuestionamiento siempre presente: ¿qué vocabulario enseñar?, pues bien, ya tenemos la respuesta: el vocabulario técnico de las disciplinas escolares y el vocabulario general de la lengua.

Continuando con nuestra presentación, la siembra de semillas y el cuido de los cultivos han producido abundantes frutos en la investigación, por ejemplo, se han inscrito y desarrollado proyectos en el Instituto de Investigaciones Lingüísticas, en el Instituto de Investigaciones para el Mejoramiento de la Educación Costarricense, hoy Instituto de Investigación en Educación, sobre lingüística educativa, rama de la lingüística que promueve en la Universidad de Costa Rica, en la década del 90 del siglo XX, don Víctor y es adoptada por sus alumnos y más cercanos colaboradores. En este ámbito se destacan los proyectos: léxico básico preescolar, léxico disponible preescolar, léxico básico primaria, léxico básico de educación secundaria, diccionario educación primaria, diccionario de la lengua española para la educación primaria costarricense, diccionario de la lengua española para la educación secundaria costarricense. Como resultado de esta generación de nuevos conocimientos en este campo se han publicado una serie de artículos científicos y libros sobre temas relativos a la enseñanza de la lengua española en el sistema educativo costarricense. 
Adicionalmente, don Víctor, contribuyó como asesor y consultor en la primera serie nacional de libros de texto de español para primaria: Serie Hacia la Luz y fue asesor, consultor y coautor en la segunda serie nacional de libros de español: Hacia el siglo XXI (1995). En ambas series se introducen, paulatinamente, cambios en los que se aprecia la presencia de un concepto de lengua como un haz dinámico de variedades y la consecuente valorización de la norma culta nacional. Como ejemplo de lo señalado se comprueba que en la serie de libros Hacia el siglo XXI el paradigma pronominal castellano se adecua al español de Costa Rica, o sea en vez de leerse la secuencia yo, tú, él/ella, nosotros, vosotros y ellos/ellas, prototípica del español peninsular, se presenta la correspondiente nuestra: yo, usted/vos, él/ella, nosotros, ustedes y ellos/ellas. Igualmente, se hace un esfuerzo por despertar una actitud de lealtad y orgullo hacia las variedades lingüísticas costarricenses.

El aporte de don Víctor en el ámbito educativo también trasciende a la política universitaria. En su función como miembro del Consejo Universitario, de octubre de 2001 a octubre de 2005, se preocupa por introducir en las políticas universitarias la proyección de la universidad en el sistema educativo nacional, tal como se lee en los 4.3. y 4.4. en las políticas universitarias del año 2005.

4.3. La Institución continuará promoviendo la integración de la educación superior estatal para fortalecer y mejorar los diferentes componentes del sistema educativo nacional.

4.4. La Universidad de Costa Rica contribuirá en el mejoramiento del sistema educativo costarricense, mediante acciones sustantivas en los niveles de preescolar, primaria y secundaria.

En el año 2006 se mantiene el mismo espíritu de proyección y compromiso con todos los niveles del sistema educativo nacional, según se consigna en ese documento.

5.6. La Institución continuará promoviendo la integración de la educación superior estatal para fortalecer y mejorar los diferentes componentes del sistema educativo nacional. Asimismo, contribuirá, de manera especial, mediante acciones sustantivas en los niveles preescolar, primaria y secundaria de las zonas de mayor rezago educativo.

Siguiendo en el transcurrir del tiempo en los años 2007 y 2008, se continúa haciendo hincapié en el necesario aporte de la universidad al sistema educativo nacional, herencia de la gestión académica y administrativa de don Víctor en el Consejo Universitario.

A partir del año 2010 se introduce la modalidad de políticas universitarias quinquenales, por lo que el actual período abarca los años del 2010 al 2014; por ventura se mantiene dentro de las proyecciones universitarias la articulación con el sistema educativo nacional y la contribución al fortalecimiento del Sistema de Educación General Pública.

La mano generosa de don Víctor lo lleva a proponer el proyecto institucional "Centro de educación continua del profesor universitario", acogido por el Consejo Universitario, el cual pese a que no se ejecutó siguiendo el espíritu original, dio origen al actual RIFED, Red Institucional de Formación y Evaluación Docente de la Universidad de Costa Rica.

Don Víctor en su función de coordinador de la Comisión de Política Académica del Consejo Universitario, año 2004, presenta el perfil del profesor universitario, en el cual se explicitan las competencias docentes, entendidas como la combinación de un saber, un saber hacer y un saber ser con los demás. Dicho perfil contempla aspectos académicos, personales y éticos, en pro de la excelencia y calidad de la formación universitaria. 
El perfil en mención no surge como un producto emergente, es la cristalización de la vivencia en una docencia en la que el conocimiento disciplinar y pedagógico dialogan en pro de una formación universitaria y profesional proyectada hacia la sociedad y el estudiante, elemento fundamental en el proceso educativo. Es, en mi opinión, el perfil docente de don Víctor, profesor que recuerda absolutamente todos los nombres, apellidos y rostros de sus alumnos, si usted, querido lector, es uno de ellos, lo habrá comprobado o tendrá ocasión de hacerlo cuando lo encuentre al lado de un diccionario o de una mata de café.

Termino tal y como empecé con el vocablo maestro, pero ahora destaco los conceptos generosidad porque don Víctor nos ha obsequiado erudición, energía, obras académicas, enseñanzas, amistad, tiempo; compromiso y responsabilidad porque ha sabido hacer universidad, o sea, ha preparado el terreno, cultivado y entregado frutos a la Universidad de Costa Rica y a la sociedad costarricense.

\section{Bibliografía}

Sánchez-Corrales, V.M. (1989). La lengua española en la educación costarricense, redefinición. Revista de Filología y Lingüística. 15 (2), 155-161.

Sánchez-Corrales, V.M. (1993). La enseñanza del español en la educación preescolar costarricense. Educación. 17 (1), 109-116.

Sánchez-Corrales, V.M. (1995). Aportes de la lingüística a la enseñanza del español como lengua materna en Costa Rica: competencia sintáctica de los preescolares. Educación. 19 (1), 73-81.

Sánchez-Corrales, V.M. y Murillo, M. (1996). Léxico básico de los preescolares de la subregión educativa de San José, Costa Rica. Káñina. 21 (2), 77-124.

Sánchez-Corrales, V.M. y Murillo, M. (1997). Características generales del vocabulario de los preescolares costarricenses (subregión educativa San José). Educación. 21 (2), 25-32.

Sánchez-Corrales, V.M. (1998). Léxico básico de los preescolares costarricenses, elementos diaintegrativos. Educación. 22 (2), 45-51.

Sánchez-Corrales, V.M. y Murillo, M. (2002a). Crecimiento del léxico básico de los escolares costarricenses: código oral. Káñina. 26 (2), 97-108.

Sánchez-Corrales, V.M. y Murillo, M. (2002b). Léxico básico de los niños preescolares costarricenses. San José: Editorial Universidad de Costa Rica.

Sánchez-Corrales, V.M. y Murillo, M. (2004). Diaintegración, contrastividad y vocabulario de los escolares costarricenses. Káñina. 23 (2), 133-146.

Sánchez-Corrales, V.M. y Murillo, M. (2005). Elementos diaintegrativos del léxico básico del escolar costarricense. Káñina. 29 (especial), 165-177.

Sánchez-Corrales, V.M. y Murillo, M. (2006). Disponibilidad léxica de los niños preescolares costarricenses. San José: Editorial Universidad de Costa Rica.

Sánchez-Corrales, V.M. y Ramírez, L. (1999). Planificación lingüística en la educación preescolar costarricense: un análisis de las políticas en la enseñanza de la lengua materna. Káñina. 23 (2), 143-153. 
Sánchez-Corrales, V.M., Rojas, M. y Víquez, A. (1997a). Español $7^{\circ}$ Guía. Serie Hacia el Siglo XXI. San José: Editorial Universidad de Costa Rica.

Sánchez-Corrales, V.M., Rojas, M. y Víquez, A. (1997b). Español $7^{\circ}$ Texto. Serie Hacia el Siglo XXI. San José: Editorial Universidad de Costa Rica.

Sánchez-Corrales, V.M., Rojas, M. y Víquez, A. (1997c). Español $8^{\circ}$ Guía. Serie Hacia el Siglo XXI. San José: Editorial Universidad de Costa Rica.

Sánchez-Corrales, V.M., Rojas, M. y Víquez, A. (1997d). Español $8^{\circ}$ Texto. Serie Hacia el Siglo XXI. San José: Editorial Universidad de Costa Rica. 
